\title{
MODELLING AND INVESTIGATION OF A DIESEL ENGINE WITH ETHANOL AND METHANOL ADDITIVES
}

\author{
Simeon Iliev \& Emil Mitev
}
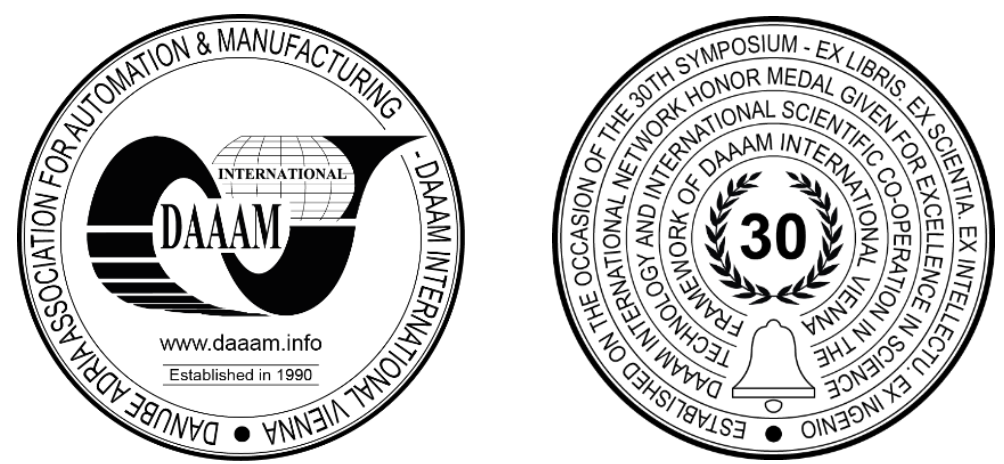

This Publication has to be referred as: Iliev, S[imeon] \& Mitev, E[mil] (2019). Modelling and Investigation of a Diesel Engine with Ethanol and Methanol Additives, Proceedings of the 30th DAAAM International Symposium, pp.0415-0423, B. Katalinic (Ed.), Published by DAAAM International, ISBN 978-3-902734-22-8, ISSN 1726-9679, Vienna, Austria DOI: $10.2507 / 30$ th.daaam.proceedings.056

\begin{abstract}
In this study, the effects of ethanol-diesel (E5, E10 and E15) and methanol-diesel (M5, M10 and M15) fuel blends on the emissions of a diesel engine were investigated. In the simulation study, the single-cylinder, four-stroke, direct injection compression ignition engine was used. The results obtained from the use of ethanol-diesel and methanol-diesel fuel blends were compared to those of pure diesel fuel (E0 and M0). One-dimensional simulation of a single-cylinder diesel engine with the help of the GT-Power software has been done. This software is capable of predicting the exhaust emissions. The simulation is designed to test the characteristics of the diesel engine working with methanol-diesel blends at full load.
\end{abstract}

Keywords: Ethanol; Methanol; Diesel Engine; Engine Simulation; Engine Emissions

\section{Introduction}

Diminishing oil reserves and increasing prices, as well as continuously rising concern over energy security, ecological problems and global warming have been identified as the most influential environmental ones. Unconventional fuels derived from resources other than oil provide a means for sustainable development, energy efficiency, energy conservation and environmental protection. Some of the alternative fuels explored are natural gas, propane, ethanol, methanol and hydrogen etc. The use of additives from oxygen-containing fuels (methanol, ethanol, butanol, biodiesel, etc.) improves the environmental performance of vehicles, but their increased share leads to a deterioration in engine power performance [1]. For this reason, they are added in small percentages so far. Some of the major additives to improve fuel efficiency are organic compounds containing oxygen (oxygenates). At present times, ethanol and methanol are promising fuels used in vehicles as an alternative to petroleum fuels [2], [3]. One reason for using ethanol and methanol is that it can be produced from natural products or waste materials, unlike petrol, which is a non-renewable fuel source.

The oxygen content in the ethanol helps to reduction of soot and particulate matter formation during the combustion. The combustion process is also enhanced by the using of ethanol-diesel blended fuels compared to the pure diesel.

Higher oxygen content and low sulphur content of methanol lead to a les pollutant emission. The higher laminar flame propagation speed leads to finishing the combustion earlier, which leads to improving the thermal efficiency of the engine.

The addition of ethanol and methanol to diesel reduces the cetane number of the blended fuel which increases the ignition delay period. Viscosity and energy density are also reduced. The dynamic viscosity of ethanol and methanol (table 2) is much lower than diesel which can cause a lubricity problem. 
From the literature review, it was concluded that the emission and performance characteristics of different blends of ethanol and methanol in different engines have not been investigated sufficiently. For this reason, this study investigated the effects of ethanol-diesel and methanol-diesel fuel blends on the performance and emissions characteristics of a compression ignition engine at different engine speed and compared them with those of the pure diesel.

Engine simulation is becoming an increasingly important engineering tool for time and cost efficiency in the development of internal combustion engines (ICEs). Most of the results that are obtained by simulation are rather difficult to be obtained experimentally. Another advantage is that the engine design parameters can easily be changed during the simulation and an optimum design condition may be recommended. The use of Computational Fluid Dynamics (CFD) simulations allow researchers to understand flow behaviour and quantify important flow parameters such as mass flow rates or pressure drops, provided that the CFD tools have been properly validated against experimental results [2].

Engine modelling is a very large subject, in part because of the range of engine configurations possible and the variety of alternative analytical techniques or sub-models, which can be applied in overall engine models. Engine modelling is a fruitful research area and as a result many research laboratories have produced their own engine thermodynamics models with varying degrees of complexity, scope and ease to use

\section{Exposition}

There are numerous studies on the use of mixtures of ethanol-diesel and methanol-diesel to power compression ignition engines, which show the advantages and some limitations resulting from such a solution. In one of the studies, the author studied the combustion, performance and emission from a four cylinder, naturally aspirated diesel engine using diesel-ethanol blends up to $15 \%$ by volume. They observed that maximum pressure, heat release rate and ignition delay period increased with the ethanol addition. Brake specific fuel consumption and brake thermal efficiency were increased with the ethanol addition. The emissions of CO, HC, NOx and PM were less with the use of ethanol diesel blends [4]. In another report [5], the author studied Euro V diesel fuel, pure biodiesel and biodiesel blended with 5\%, 10\% and 15\% of ethanol and 5\%,10\% and 15\% of methanol in a four-cylinder naturally-aspirated direct-injection diesel engine. The results showed that compared with Euro V diesel fuel, the blended fuels could lead to the reduction of both NOx and PM emissions of a diesel engine, with the methanol blends being more effective than the ethanol blends. Another authors [6] has investigated a naturally aspirated, four-stroke, single cylinder diesel engine with methanol-diesel blended fuel. They observed a reduction in $\mathrm{CO}, \mathrm{HC}$ and smoke emissions. It was reported by them, that NOx emission increased with the addition of methanol in the blended fuel. Whereas, brake specific fuel consumption was increased and brake thermal efficiency was decreased with the addition of methanol. Also, other interesting research [7] studied the performance and emission characteristics of the engine fueled with biodiesel-methanol-diesel and biodiesel-ethanol-diesel in a compression ignition engine. The results showed that biodiesel-alcohol-diesel blends had higher brake-specific fuel consumption than diesel. As alcohol concentrations in blends increased, $\mathrm{CO}$ and $\mathrm{HC}$ emissions increased, while $\mathrm{NOx}$ emissions were reduced. Also, methanol blends were more effective than ethanol blends for reducing $\mathrm{CO}$ and $\mathrm{HC}$ emissions, while NOx reduction was achieved by ethanol blends. In another study [8] conducted with a 5.9 liter diesel engine, torque was tested with two blends containing $10 \%$ and $15 \%$ ethanol. Engine power is reduced by about $8 \%$ with both fuel blends.

\begin{tabular}{ll}
\hline Description & Value \\
\hline Fuel & Diesel \\
Engine type & Single cylinder \\
Piston diameter [mm] & 87,5 \\
Piston stroke [mm] & 110 \\
Volume [cc] & 661 \\
Compression ratio & $17,5: 1$ \\
Power [kW] & 3,5 \\
Maximum rotation speed [min $\left.{ }^{-1}\right]$ & 1500 \\
Opening suction valve before TDC [0] & 4,5 \\
Closing suction valve after BDC [0] & 35,5 \\
Opening exhaust valve before TDC [0] & 35,5 \\
Closing exhaust valve after BDC [0] & 4,5 \\
\hline
\end{tabular}

Table 1. Characteristics of the diesel engine

The characteristics of the diesel engine used in the study are shown in Table 1, Figure 2 and Figure 3 shows the variation of the specific fuel consumption at different ethanol and methanol concentrations of $0 \%$ Ethanol (E0), 5\% Ethanol (E5), 10\% Ethanol (E10), 15\% Ethanol (E15), 0\% Methanol (M0), 5\% Methanol (M5), 10\% Methanol (M10), 
$15 \%$ Methanol. The study was performed at an engine speed of $1500 \mathrm{~min}^{-1}$. The results obtained show that with an increase in the ethanol and methanol concentration in the mixture (E5 - E15) and (M5 - M15) the specific fuel consumption increases, with a maximum specific consumption being obtained in mixtures with $15 \%$ ethanol E15. The lower ethanol calorific value of 26.8 and methanol caloric value of 19.7 compared to pure diesel fuel 43 (Table 1) increases the fuel consumption to obtain the same amount of energy. Also, the low density and viscosity of ethanol and methanol relative to pure diesel contributes to higher specific fuel consumption.

Figure 1 shows a single-cylinder diesel engine, developed using the GT-Power software.

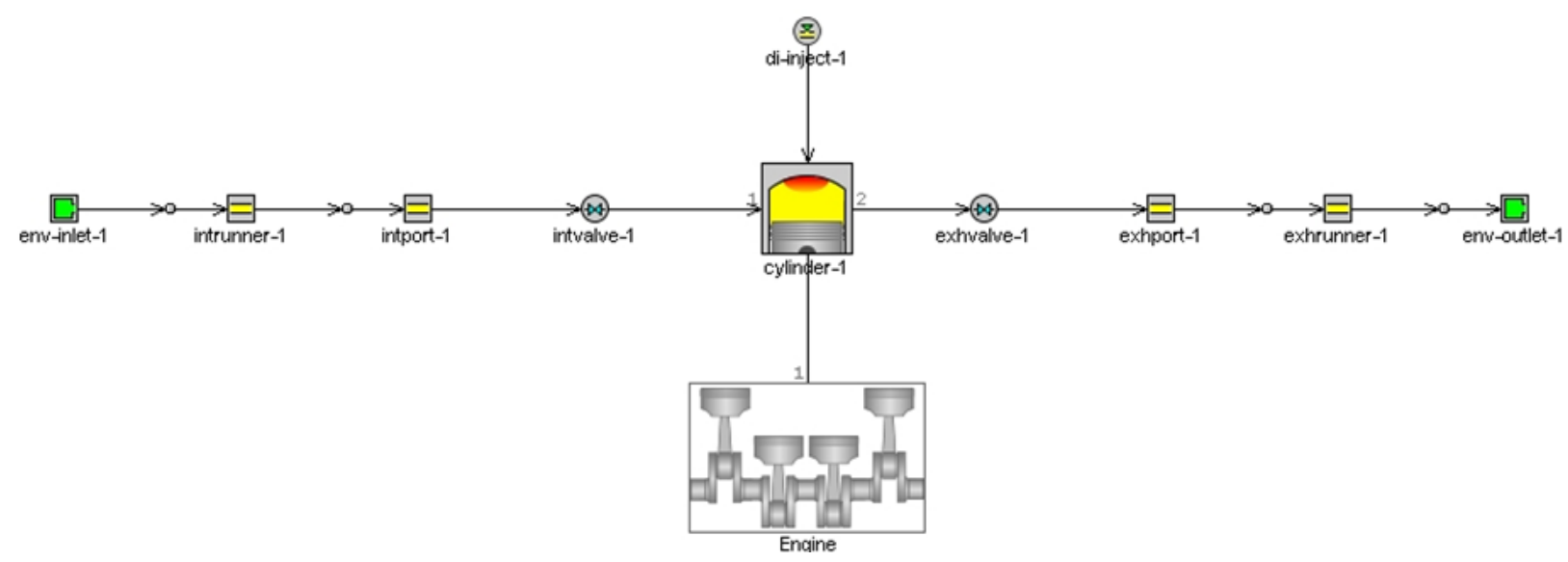

Fig. 1. Single-cylinder diesel engine model

In the table. 2 are given some of the basic properties of diesel fuel ethanol and methanol.

\begin{tabular}{llccc}
\hline Fuel properties & Unit & Diesel & Ethanol & Methanol \\
\hline Chemical formula & - & $\mathrm{C}_{10} \sim \mathrm{H}_{15}$ & $\mathrm{C}_{2} \mathrm{H}_{5} \mathrm{OH}$ & $\mathrm{CH}_{3} \mathrm{OH}$ \\
Density at $20^{\circ} \mathrm{C}$ & $\mathrm{kg} / \mathrm{m}^{3}$ & 837 & 788 & 790 \\
Cetane number & - & 50 & $5-8$ & 3,8 \\
Viscosity at $40{ }^{\circ} \mathrm{C}$ & $\mathrm{mm}^{2} / \mathrm{s}$ & 2.6 & 1,2 & 0,44 \\
Surface tension at $20{ }^{\circ} \mathrm{C}$ & $\mathrm{N} / \mathrm{m}$ & 0,023 & 0,015 & 0,023 \\
Calorific value & $\mathrm{MJ} / \mathrm{kg}$ & 43 & 26,8 & 19,7 \\
Specific heat capacity & $\mathrm{J} / \mathrm{kg}{ }^{\circ} \mathrm{C}$ & 1850 & 2100 & 2545 \\
Boiling point & ${ }^{\circ} \mathrm{C}$ & $180-360$ & 78 & 65 \\
Oxygen content & $\%$ weight & 0 & 34,8 & 37,5 \\
Latent heat of evaporation & $\mathrm{kJ} / \mathrm{kg}$ & 250 & 840 & 1178 \\
Hydrogen content & $(\mathrm{wt} \%)$ & $\sim 14$ & 13 & 1300 \\
Fuel-air attitude & - & 15,0 & 9,0 & 6,47 \\
Molecular weight & $\mathrm{kg}$ & 170 & 46 & 32 \\
\hline
\end{tabular}

Table 2. Essential properties of diesel and ethanol 


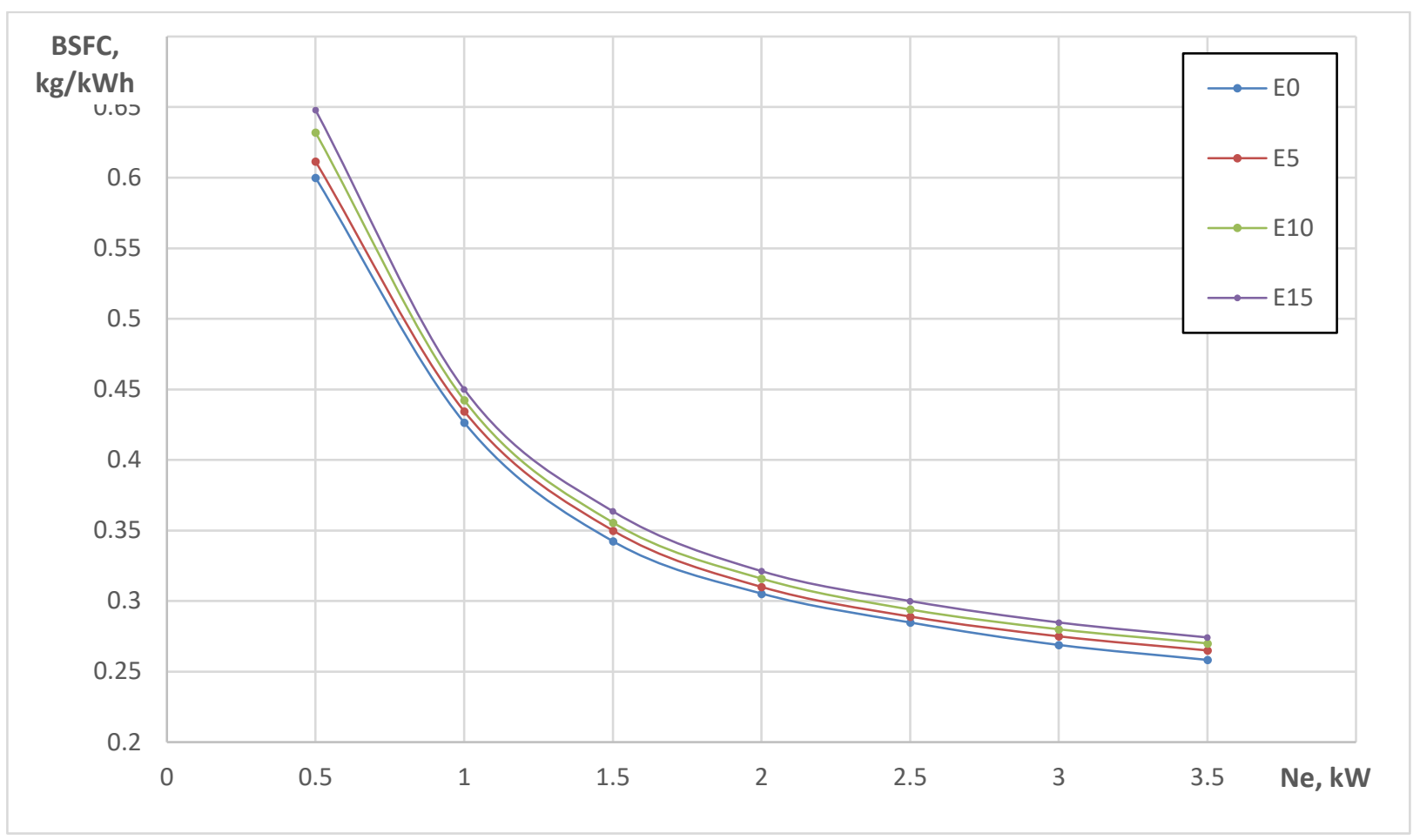

Fig. 2. Specific fuel consumption variation at different concentrations of ethanol

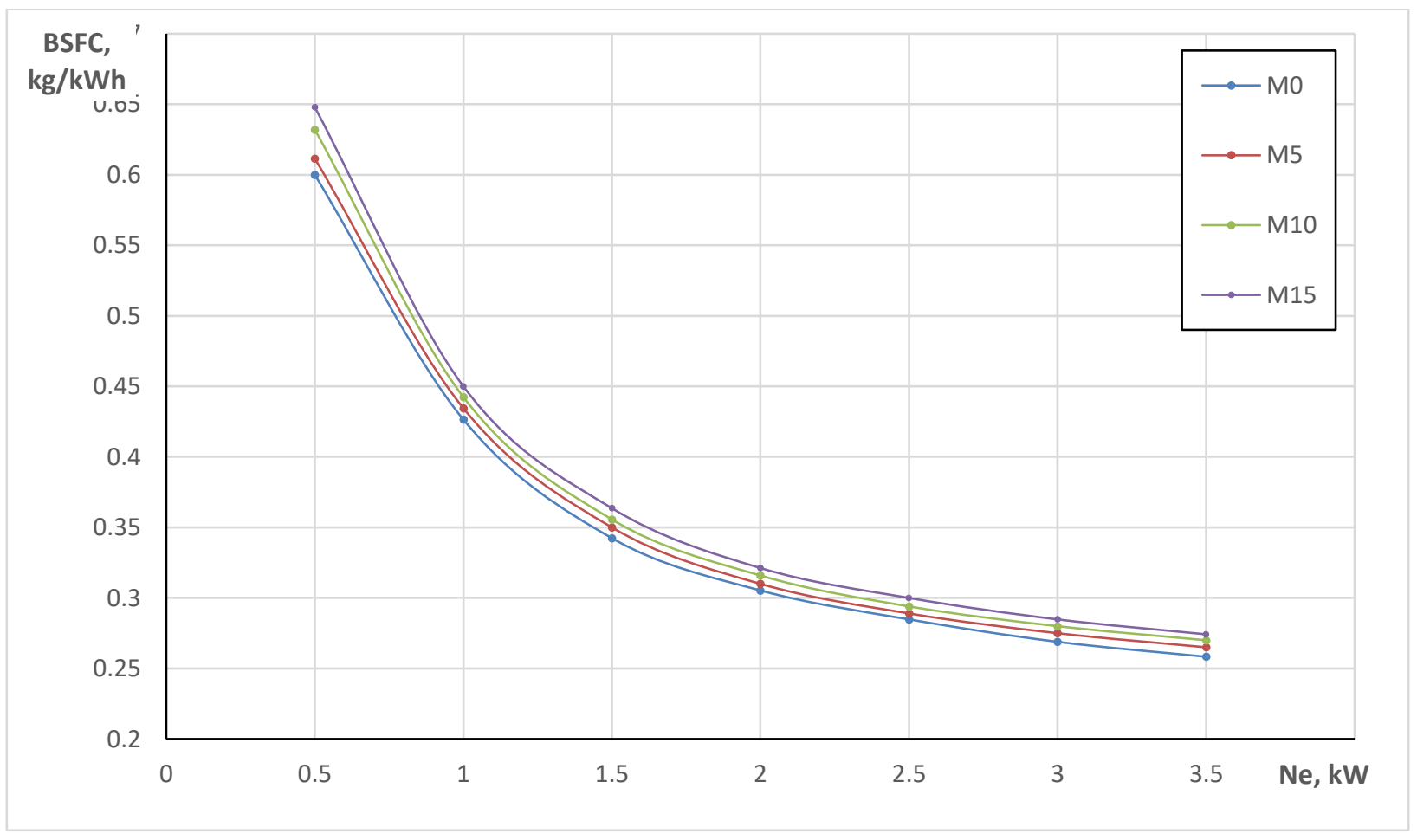

Fig. 3. Specific fuel consumption variation at different concentrations of methanol

Figure 4 and Figure 5 shows the variation of the exhaust gas temperature of the engine at a different concentration of ethanol and methanol. From the results obtained, it becomes clear that with the increase of the load the temperature of the exhausted gas increases. With an increase in the ethanol and methanol content (E10 - E15) and (M10 - M15), a slight increase in the exhaust gas temperature is noticeable and is the highest at E15 and M15. This can be explained by the improvement of the combustion process due to the presence of oxygen in the ethanol mixtures. Higher latent heat of ethanol evaporation is the other factor that influences the reduction of exhaust temperature. 


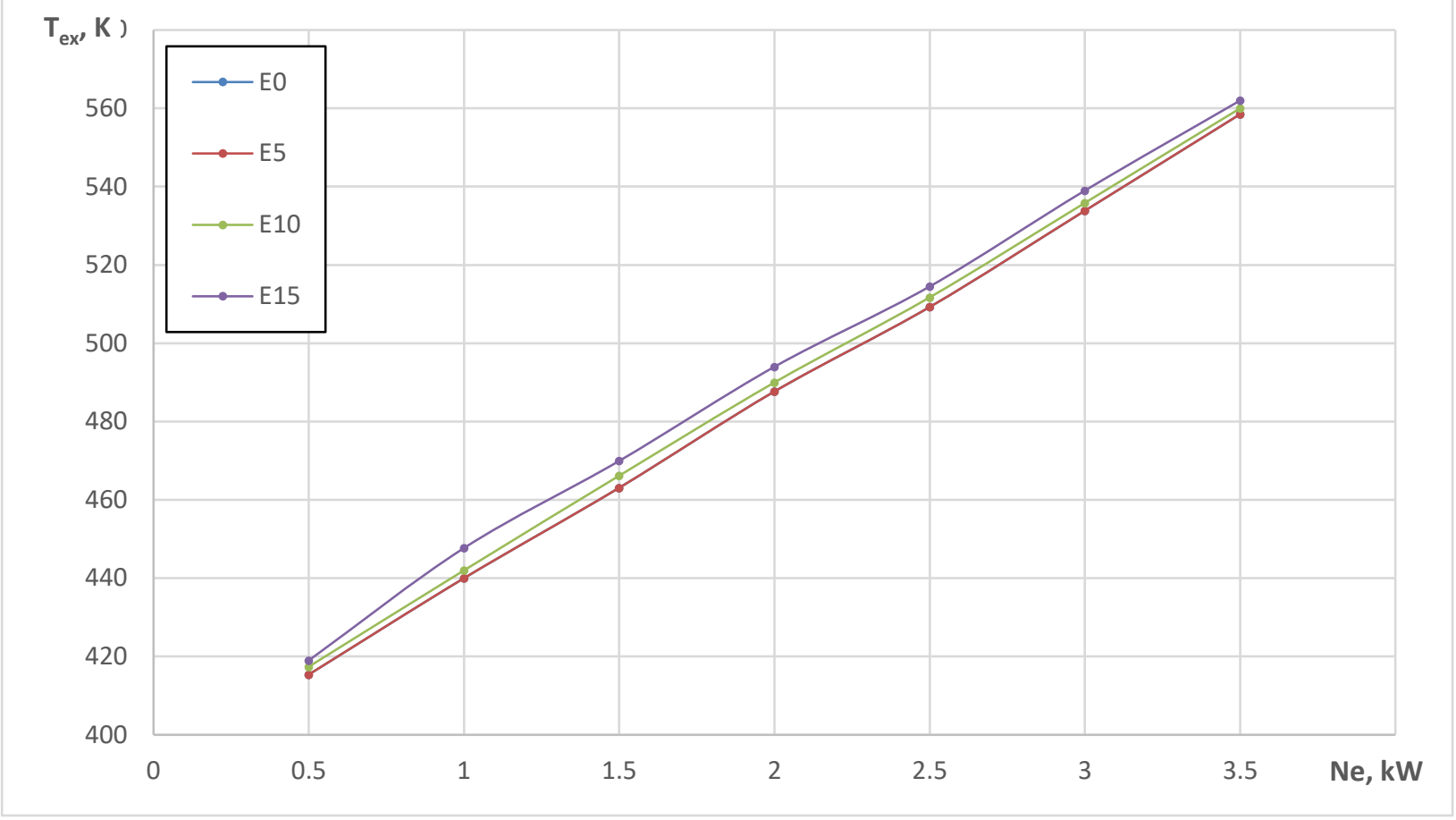

Fig. 4. Exhaust gases temperature variation at different ethanol concentrations

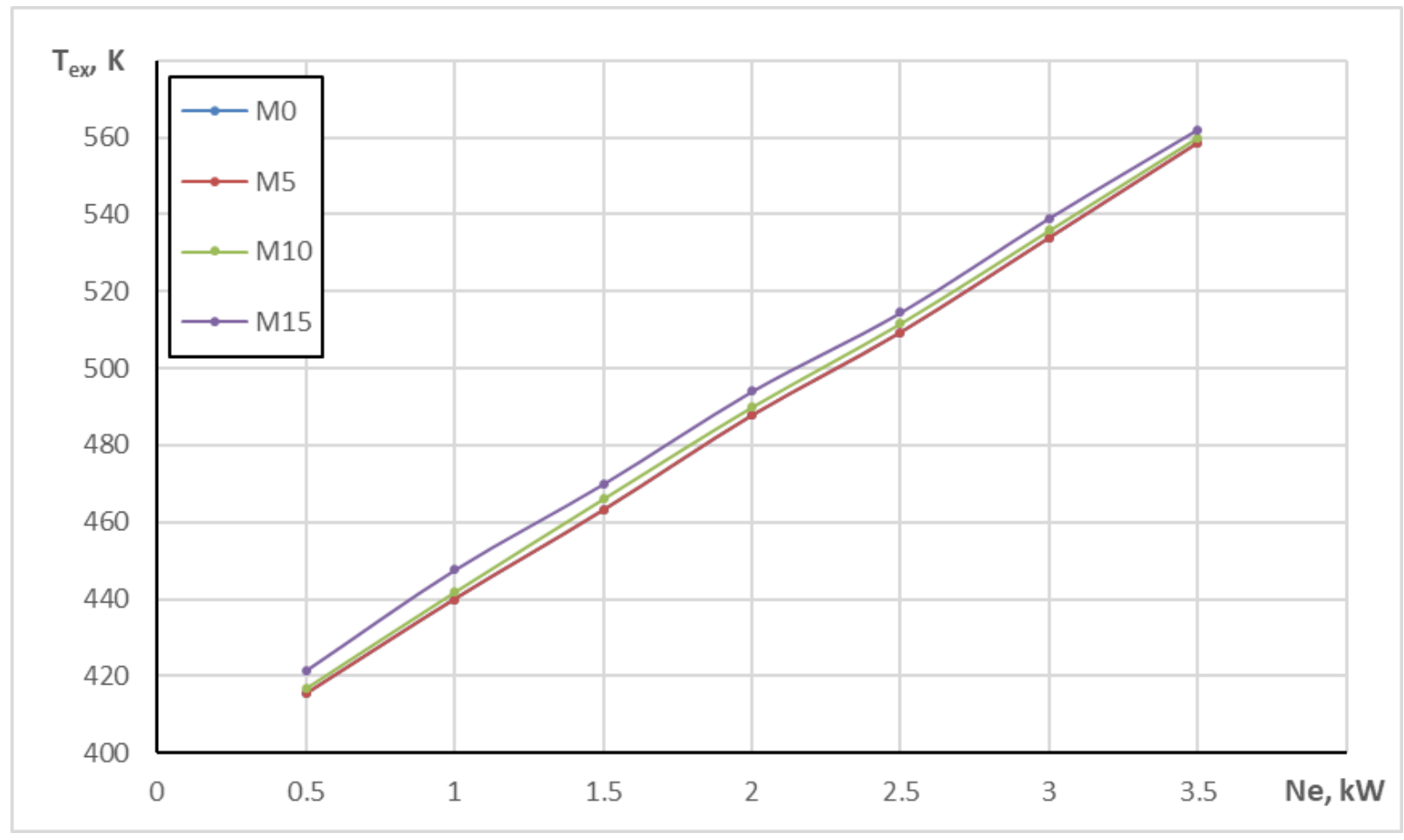

Fig. 5. Exhaust gases temperature variation at different methanol concentrations

The variation of the ignition delay period at different concentrations of ethanol and methanol is shown in Fig. 6. By increasing the ethanol and methanol content in the mixture (E5 - E15) and (M5 - M15) the cetane number of the mixture is reduced resulting in an ignition delay period. At full load, the ignition delay period of pure diesel fuel is 15,620 compared to the E15 mixture, which is 23,120 and M15 mixture, which is 23,120. The longer ignition delay period of ethanol and methanol mixtures results in the formation of poorer mixtures, which in turn leads to a decrease in the combustion temperature and a reduction in the formation of nitrogen oxides. 


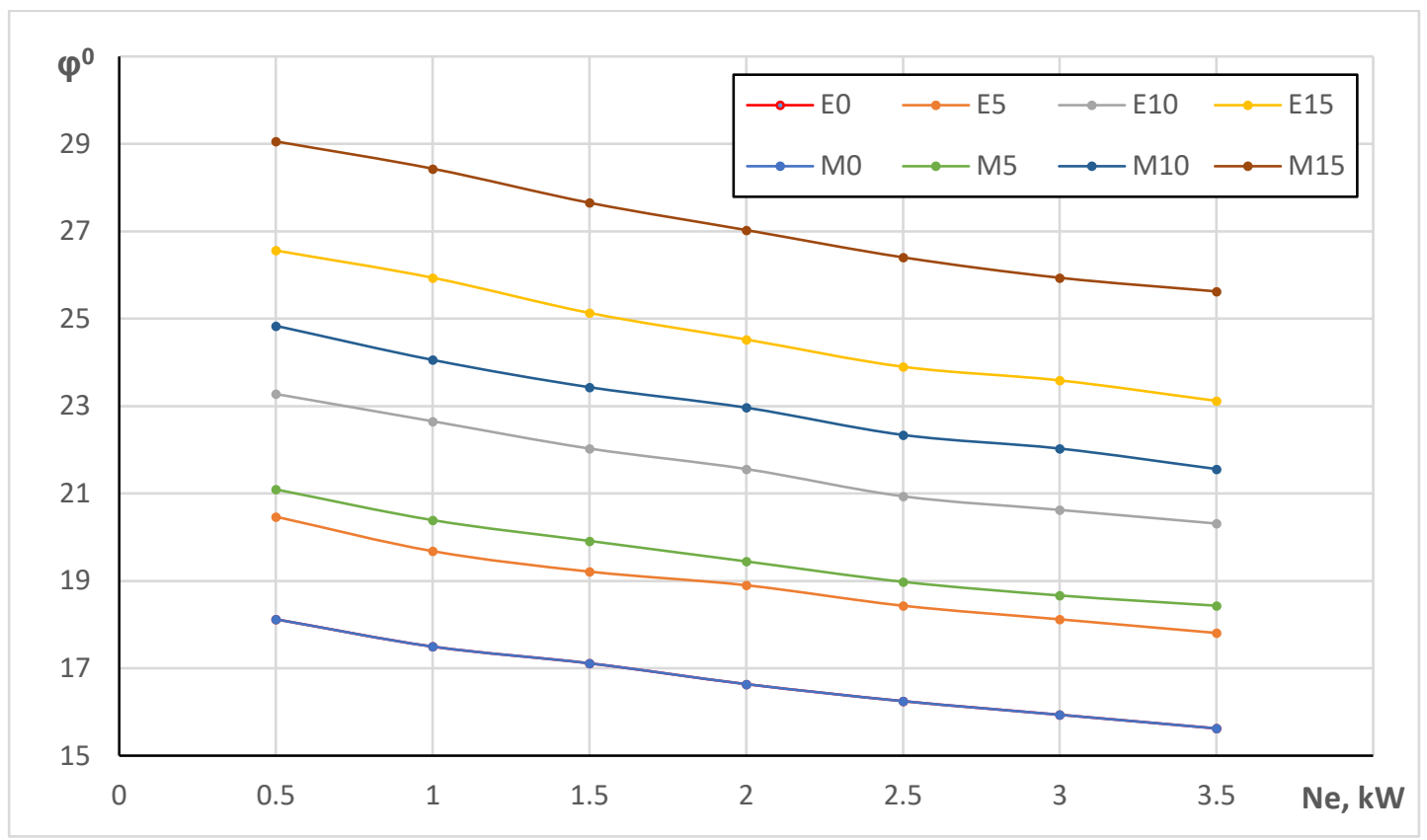

Fig. 6. Variation of the ignition delay period at different concentrations of ethanol and methanol

The in-cylinder pressure variation, depending on the crankshaft angle, at different ethanol and methanol concentrations, is shown in Fig. 7. From the results obtained, it can be seen that the maximum pressure for pure diesel fuel is $7.96 \mathrm{MPa}$ at $50^{\circ}$ after TDC, for the mixture E5 is $7.8 \mathrm{MPa}$ at $50^{\circ}$ after TDC, for the mixture E10 is $7.56 \mathrm{MPa}$ at $60^{\circ}$ after TDC and for E15 is $7.15 \mathrm{MPa}$ at $70^{\circ}$ after TDC. For methanol mixtures: maximum in-cylinder pressure M5 is 7.7 $\mathrm{MPa}$ at $8^{\circ} \mathrm{C}$ after TDC, for the mixture $\mathrm{M} 10$ is $7.38 \mathrm{MPa}$ at $6^{\circ} \mathrm{C}$ after TDC and for M15 is $6.72 \mathrm{MPa}$ at $6^{\circ} \mathrm{C}$ after TDC. Due to the lower cetane number of mixtures with ethanol (E5 - E15) and methanol (M5 - M15) the start of the combustion process occurs later. Increasing the methanol content of the mixture, the cetane number of the blends gets lowered and causes increase in ignition delay. That could lead to burn more fuel in the premixed phase of combustion, thus the rate of pressure rise increases and peak pressure decreases.

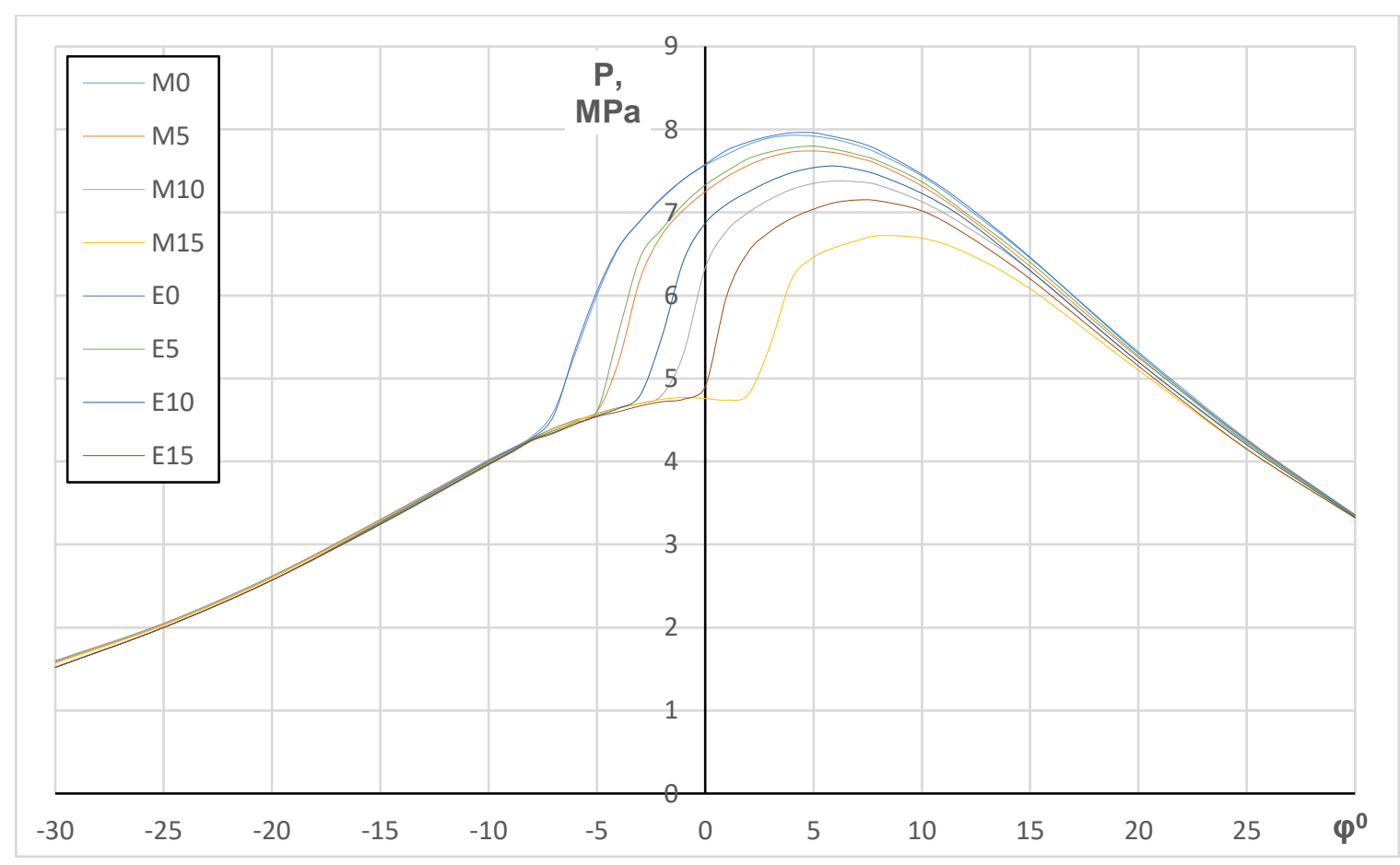

Fig. 7. In-cylinder pressure variation depending on the crankshaft angle with different concentrations of ethanol and methanol 
Figure 8 shows the variation of NOx emissions depending on the ethanol and methanol concentration in the diesel fuel mixture. As the ethanol and methanol concentration increases in the mixture, NOx decreases due to the low latent heat of evaporation of the mixture. Another possible cause is the formation of a lean mixture, which leads to a decrease in the combustion temperature. The decreasing of NOx emissions is more with ethanol for the same percentage of the blends.

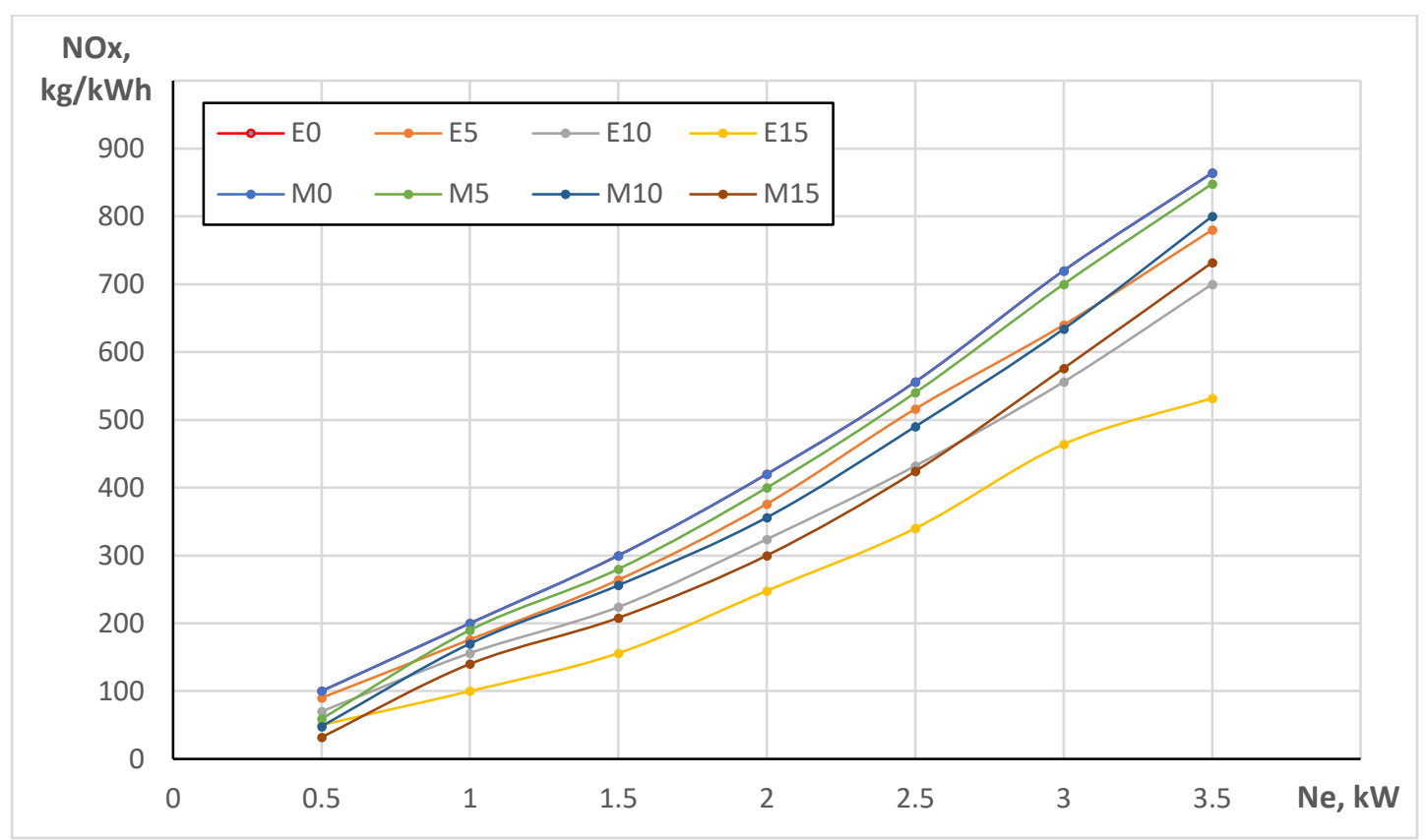

Fig. 8. Variation of NOx emissions at different concentrations of ethanol and methanol

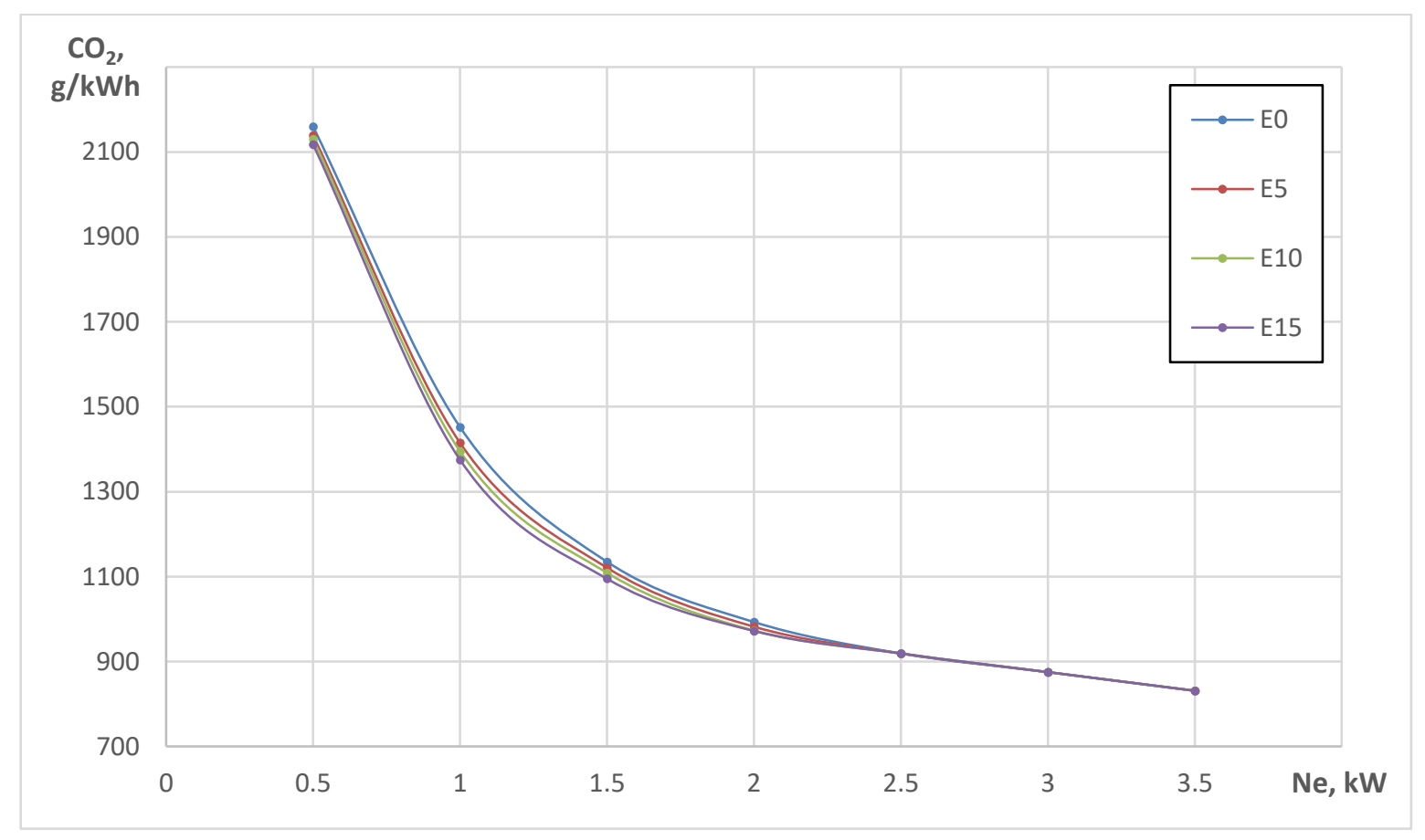

Fig. 9. Variation $\mathrm{CO}_{2}$ emissions at different concentrations of ethanol

The $\mathrm{CO}_{2}$ variation at different concentrations of ethanol and methanol is shown in Fig. 9 and Fig. 10. The figures show that blending diesel fuel with ethanol and methanol results in $\mathrm{CO}_{2}$ reduction at low loads. Increasing the ethanol and methanol content of the mixture reduces the $\mathrm{C} / \mathrm{H}$ ratio and increases the $\mathrm{O}_{2}$ content in the cylinder. This circumstance creates a condition for a lean mixture and reduces the temperature at the end of the combustion process. Also, the reduction of $\mathrm{CO}_{2}$ occurs in parallel with a decrease in the $\mathrm{C} / \mathrm{H}$ ratio. 
With low engine load, the combustion temperature is insufficient to initiate full combustion, resulting in an increase in $\mathrm{CO}_{2}$ emissions for all tested fuels and mixtures. However, at higher loads, combustion temperatures are high enough to achieve fuller combustion, resulting in a reduction in $\mathrm{CO}_{2}$ for all tested fuels and mixtures. The reduction of $\mathrm{CO}_{2}$ emissions has also been reported by other researchers [9].

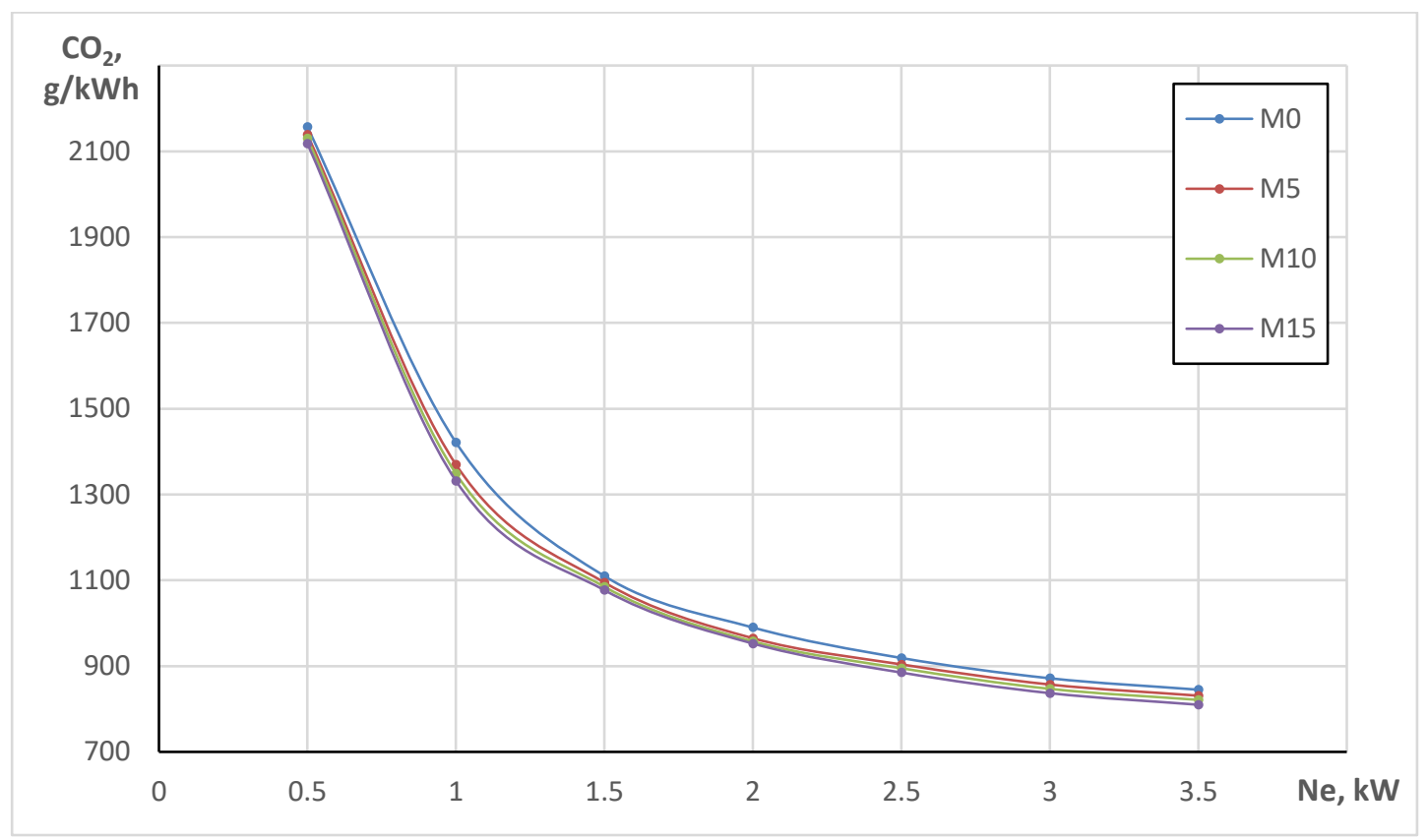

Fig. 10. Variation $\mathrm{CO}_{2}$ emissions at different concentrations of methanol

\section{Conclusion}

The main purpose of this study is to investigate the effect of using ethanol-diesel and methanol-diesel fuel blends on the diesel engine characteristics. According to the simulation results, it can be concluded that:

1. By increasing the ethanol and methanol concentration in the mixture (E5-E15) and (M5-M15), the specific fuel consumption increases, with a maximum specific fuel consumption being obtained in mixtures with $15 \%$ ethanol E15.

2. With an increase in the ethanol and methanol concentration in the mixture, a slight increase in the exhaust gas temperature is observed in comparison with pure diesel.

3. Increasing the ethanol and methanol content of the mixture (E5 - E15) and (M5 - M15) reduces its cetane number, resulting in a long ignition delay period. At full load, the ignition delay period for pure diesel fuel is 15,620 compared to the E15 mixture, which is 23,120 and for M15 mixture is 23,120 .

4. The maximum in-cylinder pressure for pure diesel fuel is $7.96 \mathrm{MPa}$ at $50^{\circ}$ after TDC, for the mixture E5 is $7.8 \mathrm{MPa}$ at $50^{\circ}$ after TDC, for E10 is $7.56 \mathrm{MPa}$ at $60^{\circ}$ after TDC and for E15 is $7.15 \mathrm{MPa}$ at $70^{\circ}$ after TDC, for the mixture M5 is 7.7 $\mathrm{MPa}$ at $80^{\circ}$ after TDC, for M10 is $7.38 \mathrm{MPa}$ at $60^{\circ}$ after TDC and for M15 is $6.72 \mathrm{MPa}$ at $80^{\circ}$ after TDC. Due to the lower cetane number of mixtures with ethanol (E5 - E15) and methanol (M5 - M15) the start of the combustion process occurs later

5. With an increase in the ethanol and methanol concentration, the NOx emissions decreases, due to the low latent heat of evaporation of the mixture. Another possible cause is the formation of lean mixture, which leads to a decrease in the combustion temperature.

6. Increasing the ethanol concentration in the mixture results in $\mathrm{CO}_{2}$ reduction at low loads.

As the future plan of the experiment team will investigate behaviour of diesel engine model with butanol additives and their impact on exhaust emissions.

\section{Acknowledgments}

The study was supported by contract of University of Ruse "Angel Kanchev”, № BG05M2OP001-2.009-0011-C01. Support for the development of human resources for research and innovation at the University of Ruse "Angel Kanchev". The project is funded with support from the Operational Program" Science and Education for Smart Growth 2014 - 2020" financed by the European Social Fund of the European Union.

The present document was supported with the financial assistance of the Project 2019-RU-03. 


\section{References}

[1] Iliev, S. (2019). Comparison of Ethanol and Methanol Blending with Gasoline Using Engine Simulation, Biofuels Challenges and opportunities, Mansour Al Qubeissi, IntechOpen, DOI: 10.5772/intechopen.81776.

[2] Iliev, S., A. (2018). Comparison of Ethanol, Methanol and Butanol Blending with Gasoline and Relationship with Engine Performances and Emissions, Proceedings of the 29th DAAAM International Symposium, pp.0505-0514, B. Katalinic (Ed.), Published by DAAAM International, ISBN 978-3-902734-20-4, ISSN 1726-9679, Vienna, Austria

[3] Iliev, S. (2014). Developing of a 1-D combustion model and study of engine performance and exhaust emissions using ethanol-gasoline blends, IAENG Transaction of Engineering Technologies, Netherlands, Springer, 2014 ,

[4] Zhu L, Cheung CS, Zhang WG, Huang Z. (2011). Combustion, performance and emission characteristics of a DI diesel engine fueled with ethanol-biodiesel blends, Fuel. 90 1743-1750;

[5] Zhu L, Cheung CS, Zhang WG, Huang Z. (2010). Emission's characteristics of a diesel engine operating on biodiesel and biodiesel blended with ethanol and methanol. Sci Total Environ 2010; 408:914-21;

[6] Sayin, C. (2010). "Engine performance and exhaust gas emissions of methanol and ethanol-diesel blends", Fuel, 89, 2010, pp. 3410-3415.;

[7] Yilmaz N. (2012). Comparative analysis of biodiesel-ethanol-diesel and biodiesel-methanol-diesel blendsinadieselengine.Energy2012; 40:210-3.;

[8] Kass, M. D., Thomas, J. F., Storey, J. M., Domingo, N., Wade, J., Kenreck, G. (2001). Emissions from a 5.9 liter diesel engine fueled with ethanol diesel blends. SAE Technical Paper 2001-01-018 (SP- 1632).);

[9] Ghadikolaei, M. (2018). Study of combustion, performance and emissions of diesel engine fueled with diesel/biodiesel/alcohol blends having the same oxygen concentration. Energy, Elsevier, Volume 157, 15 August 2018, Pages 258-269. 